\title{
EL CONFLICTO ENTRE LOS DERECHOS FUNDAMENTALES DEL TRABAJADOR Y LA LIBERTAD DE EMPRESA: EL NECESARIO TRÁNSITO DESDE EL JUICIO DE PROPORCIONALIDAD AL JUICIO DE PONDERACIÓN
}

\author{
SANTIAGO GONZÁLEZ ORTEGA* \\ Universidad Pablo de Olavide de Sevilla, España
}

\begin{abstract}
RESUMEN: En este artículo se analiza la modalización de los derechos fundamentales dentro de las relaciones laborales, y se critica las herramientas jurídico-argumentativas utilizadas para resolver los conflictos de derechos fundamentales dentro de la empresa. Para el autor, el pricipio de proporcionalidad en sentido amplio (idoneidad y necesidad) constituye una herramienta sesgada ante el problema de la colisión de derechos fundamentales, pues parte de la base de la legitimidad de las medidas patronales, otorgando a priori preponderancia a la libertad de empresa. En relación con esto, el autor postula que el criterio más adecuado y que se ha de aplicar en los conflictos de derechos fundamentales, entre el empresario y trabajador, es el de proporcionalidad en sentido estricto o ponderación.
\end{abstract}

Palabras clave: Eficacia horizontal, ciudadania en la empresa, eficacia directa, principio de proporcionalidad, ponderación de derechos fundamentales.

\begin{abstract}
This article analyzes the fundamental rights modalization in labor relations, and criticises the juridical-argumentative tools used to solve conflicts of fundamental rights within the company. For the author, the priciple of proportionality in the broad sense (suitability and necessity) is a tool skewed to the problem of the collision of fundamental rights, because it starts on the basis of the legitimacy of the employer's actions, giving prominence a priori to freedom of enterprise. Related to this, the author argues that the most appropriate approach that must be applied in fundamental conflicts between the employer and employee, is the proportionality in the strict sense, or weighting.
\end{abstract}

Key words: Horizontal efficacy, citizenship in the company, direct efficacy, proporcionality principle, weighting of fundamental rights.

\section{INTRODUCCIÓN}

Nadie podrá negar que la empresa es un ámbito donde los derechos fundamentales de los trabajadores pueden sufrir limitaciones, encontrar obstáculos para su normal ejercicio o, incluso, soportar una prohibición absoluta. Y tampoco podrá rechazarse el hecho de que esas restricciones encuentran su fundamento en la posición de supremacía que el empresario ostenta en la organización productiva de la que es su titular o propietario. El trabajador se inserta así, mediante el contrato de trabajo, en una organización de titularidad y control ajenos, dentro de la cual se ubica en una posición jurídica debilitada como muy expresivamente se manifiesta en la calificación de su trabajo como subordinado o dependiente. El empresario, en cambio y como consecuencia de su titularidad sobre la empresa, está dotado de facultades que evidencian con claridad su posición preeminente como son, en una enumeración no exhaustiva, los poderes de contratación, de dirección y de organización, de

Catedrático de Derecho del Trabajo y de la Seguridad Social. Universidad Pablo de Olavide de Sevilla, España 
determinación concreta de la prestación debida, de cambio de las condiciones de trabajo, de control de la actividad laboral, y de sanción y disciplina. Estos poderes empresariales, en gran parte generales u organizacionales, se ejercitan también en lo concreto de cada relación laboral a través de las facultades empresariales de especificación, de modificación y de disciplina individual, estando el trabajador voluntariamente sometido a todos ellos mediante el contrato de trabajo. En consecuencia, es la asimetría, tanto fáctica como jurídica, de las posiciones de empresario y trabajador lo que hace que, para el contratante débil que no es obviamente otro que el trabajador, su incorporación a la organización productiva de la empresa suponga una muy posible y habitual fuente de limitaciones al ejercicio por su parte de los derechos fundamentales; particularmente cuando ese ejercicio puede tener repercusión sobre el funcionamiento de la empresa o afectar a sus intereses o a su rendimiento. La empresa es por tanto un indudable ámbito de riesgo o una zona de especial peligrosidad ya que, en ella, los derechos fundamentales de los trabajadores son vistos como "cuerpos extraños", siendo la organización empresarial un espacio poco favorable a su ejercicio, y dando origen a una situación que se ha calificado como de "difícil convivencia" .

Que lo anterior no es solo una hipótesis teórica sino una realidad cotidiana se puede apreciar en la enumeración de casos que se hace a continuación, siendo todos ellos conflictos concretos que en algún momento han sido abordados por diversas instancias judiciales españolas. Así: la discriminación en la contratación por razones de sexo o de edad; la pretensión empresarial de investigar a fondo e indiscriminadamente el estado de salud del trabajador como condición para su contratación; la prohibición de afiliarse, o de no afiliarse, a un determinado sindicato como requisito para el mantenimiento del contrato; los obstáculos al desarrollo de la actividad sindical en la empresa; la discriminación en los ascensos por razón de raza o nacionalidad; el despido por participación en una huelga; la imposición al trabajador de un determinado aspecto físico o de un uniforme concreto en el desarrollo de su actividad laboral; la prohibición de profesar o de practicar una concreta religión en la empresa; el registro personal o de las taquillas y de las propiedades del trabajador; el acoso sexual y psicológico; toda la gama posible de discriminaciones por razón de sexo o de la orientación sexual; la represión del ejercicio de las libertades de información y de expresión en la empresa y fuera de ella; el uso y la difusión de información reservada acerca del trabajador, a veces con una finalidad denigratoria; los obstáculos e impedimentos a la convocatoria de huelgas; la intervención de los correos electrónicos de los trabajadores y la obtención de información precisa del uso que se hace de los medios informáticos; la grabación de imágenes o conversaciones, incluso privadas, de los trabajadores; la represalia al trabajador que ha presentado algún tipo de reclamación administrativa o judicial; la imposición de comportamientos que afectan a la vida privada, o la prohibición de algunos, incluso fuera de la empresa y en la esfera de la vida personal del trabajador, etc.

En estos casos, y en otros similares, son los derechos fundamentales a la igualdad, a no ser discriminado, a las libertades ideológicas (políticas, personales, sindicales, religiosas), a la intimidad en todas sus manifestaciones (intimidad física, secreto de las comunicaciones,

\footnotetext{
Valdés Dal-Re, F. "Contrato de trabajo, derechos fundamentales de la persona del trabajador y poderes empresariales: una difícil convivencia”, en: Relaciones Laborales, España, 2003/II, pp. 89 y ss.
} 
control del tratamiento, uso y difusión de datos íntimos, intimidad informática), al honor, a la propia imagen (como elección del propio aspecto personal y como resistencia a la captación y difusión por la empresa de imágenes personales), a la libertad sindical, a la tutela judicial, a la huelga, a la educación (en su vertiente de derecho general a la educación, o más particularmente en su dimensión de formación en beneficio de la promoción profesional), o, en fin, a la vida y a la integridad física, los que están en juego al soportar la presión limitativa que se deriva de los poderes empresariales y de la función de estos poderes de lograr la satisfacción de los intereses económicos de la empresa. El conflicto, pues, se concreta entre el ejercicio de los derechos fundamentales del trabajador y los intereses de la empresa en cuyo seno se pretende dicho ejercicio. Unos intereses estos últimos que también obtienen tutela constitucional y que parten del reconocimiento, igualmente a nivel constitucional, del derecho de propiedad así como de la libre iniciativa económica privada y de la libertad de empresa en una economía de mercado. De lo que se desprende también la aspiración legítima de la empresa a la tutela de la productividad y del rendimiento, a lo que están orientados, y esta es su funcionalidad, los variados poderes empresariales de cuyo ejercicio derivan, como se ha indicado, las posibles limitaciones de los derechos fundamentales del trabajador.

\section{LOS RASGOS BÁSICOS DE LOS DERECHOS FUNDAMENTALES. SU EFICACIA DIRECTA EN LAS RELACIONES ENTRE PRIVADOS COMO CARACTERÍSTICA CENTRAL}

Frente a situaciones como las descritas, el Tribunal Constitucional español (TC, a partir de ahora) ha venido sosteniendo, y es algo que difícilmente no puede compartirse, que la celebración de un contrato de trabajo "no implica en modo alguno la privación para una de las partes, el trabajador, de los derechos que la Constitución le reconoce como ciudadano" (STC 98/2000, de 10 de abril), ya que no pierde esa condición "al insertarse en el ámbito de una organización privada" (STC 88/1995, de 19 de julio), en la medida en que las organizaciones empresariales "no forman mundos separados y estancos del resto de la sociedad" (STC 196/2004, de 15 de noviembre); de manera que no son legítimos "los despojos transitorios o las limitaciones injustificadas de sus derechos fundamentales y libertades públicas, que tienen un valor central en el sistema jurídico constitucional" (STC 106/1996, de 12 de junio). Dicho sintéticamente, el trabajador, titular como ciudadano de derechos fundamentales y de libertades públicas de rango constitucional, y ya se trate de derechos fundamentales genéricos o específicamente laborales, no pierde ni ve suspendida esa titularidad por el hecho de insertarse en la organización empresarial y someterse a sus exigencias. Pero, lógicamente, no se trata solo de la titularidad del derecho sino también de lo que esa titularidad significa y hace que el derecho mismo pase de una situación virtual o potencial a otra actual o práctica (sea, en definitiva, eficaz) como es el ejercicio mismo del derecho y su satisfacción. En consecuencia, la condición de trabajador dependiente no puede suponer un obstáculo absoluto ni a la titularidad ni al ejercicio de sus derechos fundamentales en el ámbito de la empresa o en espacios que pudieran tener repercusión sobre la misma. 
Las afirmaciones anteriores se apoyan en la identificación de una serie de rasgos básicos de los derechos fundamentales como son los de su universalidad, su centralidad, su eficacia directa y su irrenunciabilidad o indisponibilidad, amén de su virtualidad en el contexto no solo de la relación entre el ciudadano y el poder público sino también en ámbito de cualquier relación jurídica privada como es la laboral.

Se trata, pues, de derechos que son universales en la medida en que se asocian a la condición de ciudadanía y se reconocen a todas las personas sin distinción alguna basada en circunstancias personales, sociales, económicas o profesionales ${ }^{2}$. Lo que incluye, desde luego, a los derechos que pertenecen a la persona y que, más allá de la mera ciudadanía, son imprescindibles para la garantía de la dignidad humana, como sucede con el derecho a la vida y a la integridad física y moral, al honor, a la libertad ideológica en cualquiera de sus versiones, a la intimidad en todas sus variantes, a la libertad y a la seguridad, a no ser discriminados por condiciones personales concretas como la raza, el sexo, la religión o la edad, o a la tutela judicial; pero también los derechos a los que el propio texto constitucional puede atribuir la condición de fundamentales como la libertad sindical o el derecho de huelga, concebidos como derechos laborales de organización y de acción, en su doble dimensión individual y colectiva. De cualquier modo, será, en cada caso, el texto fundamental el que establecerá el repertorio de derechos que, considerados como fundamentales, se atribuyen a todos los ciudadanos ya que el tratamiento del posible conflicto de estos derechos con los intereses de la empresa está muy condicionado por la existencia de un reconocimiento constitucional expreso de los mismos. En segundo lugar, se trata de derechos centrales porque expresan principios y valores que constituyen el fundamento de toda la organización política y jurídica de un país y que se condensan en el texto constitucional, intermediario entre las concepciones puramente valorativas o morales y la realidad jurídica o normativa.

En tercer lugar, los derechos fundamentales están dotados de eficacia directa porque no son meras declaraciones programáticas pendientes del desarrollo legal, y no requieren de la intermediación del legislador ordinario para ser vinculantes y constituir auténticos derechos subjetivos perfectos; de forma que su reconocimiento constitucional como tales derechos fundamentales es suficiente para que sean inmediatamente aplicados y ejercidos así como para reclamar su respeto. Con este rasgo de la eficacia directa se evitan dos consecuencias negativas para la efectividad de los derechos fundamentales: de un lado, su degradación normativa desde la condición de derechos subjetivos a la de meros principios orientadores si solo fueran aplicables y exigibles tras su desarrollo normativo por parte del legislador ordinario; de otra parte, el que esa efectividad dependa de la decisión del poder legislativo que podría, por hipótesis, retrasar indefinidamente la eficacia práctica de tales derechos con solo demorar su regulación por ley. Los derechos fundamentales de naturaleza constitucional no pueden quedar sometidos a contingencias de diverso tipo (sociológicas, económicas, de oportunidad política) que, en cambio, sí pueden condicionar otros derechos constitucionales, no fundamentales en sentido propio, cuya aplicación real está sometida a intermediación legal, de forma que solo podrían ser alegados como tales derechos subjetivos

2 Gutiérrez Pérez, M. Ciudadania en la empresa y derechos fundamentales inespecíficos. Murcia, España: Editorial Laborum, 2011. 
en los términos, el tiempo y la medida en que así lo estableciera la norma de desarrollo. Esto no quiere decir que los derechos fundamentales no puedan ser regulados por la ley pero sí que, primero, esa regulación no es indispensable para su efectividad; $y$, segundo, que la intervención del legislador debe respetar siempre el que se considera como contenido esencial del derecho, tal y como está regulado en la propia norma constitucional ya que la garantía del contenido del derecho se proyecta también como límite constitucional a la labor del legislador.

En cuarto lugar, los derechos fundamentales son irrenunciables ya que no se puede perder su titularidad por una decisión voluntaria, mucho menos impuesta; como tampoco, salvo casos absolutamente excepcionales, puede disponerse de ellos ya que la renuncia a su ejercicio constituye un comportamiento contrario a los valores constitucionales que reclaman un disfrute efectivo de esos derechos como condición de una convivencia sana, digna, democrática y respetuosa con la condición humana. Ejemplos de esa disposición excepcional podrían ser los del derecho a la vida o a la integridad física de la madre para salvar la vida del feto o de los profesionales de la seguridad para preservar los derechos fundamentales de otros; o al ejercicio temporal del derecho de huelga como aportación a la estabilidad y buena marcha de la economía o de la empresa; o a la libertad sindical por el desempeño de funciones públicas de autoridad o de policía o seguridad; o a la expresión públicas de las propias convicciones en el caso de los trabajadores de las organizaciones ideológicas o de tendencia; o a la intimidad personal a cambio de una compensación económica. La indisponibilidad general del derecho fundamental funciona, por tanto, como una cláusula de efectividad y de tutela del ejercicio del derecho incluso contra la propia voluntad de su titular como sucedería, por ejemplo, el caso de la renuncia a un derecho fundamental del trabajador como condición para obtener un empleo o para mantenerlo; mucho más en este caso en el que la posición de inferioridad del trabajador está tratada por la legislación ordinaria a través también de la prohibición de renuncia de los derechos que las normas le atribuyen.

En quinto lugar, a los rasgos anteriores ha de añadirse el crucial de la virtualidad y eficacia de los derechos fundamentales en las relaciones entre privados, constituyendo lo que se ha calificado como eficacia horizontal. Es cierto que se trata de una característica largamente debatida pero hoy generalmente aceptada. Como es sabido, en las distintas fases de evolución del constitucionalismo, los derechos fundamentales han pasado por diversas etapas. Así, surgieron, conforme al enfoque exclusivamente individualista del momento, con la función de constituir un valladar de la persona o del sujeto privado frente al poder político, reclamando del mismo una mera abstención o respeto a estos derechos que se conectan con la dignidad humana y que constituyen la expresión más aquilatada de la personalidad. La ampliación de número de los derechos fundamentales así como la variedad de su naturaleza (derechos individuales, colectivos o sociales; derechos de abstención o prestacionales; derechos de disfrute personal o de acción, individual o colectiva) han determinado que se sostenga atinadamente que la satisfacción efectiva del derecho de que se trate no se agota en la relación con el poder público sino que ha de extenderse a cualquier otro tipo de relación jurídica que el sujeto pueda entablar, al margen de si es con sujetos públicos o privados.

Se trata de la otra dimensión de la universalidad del derecho fundamental, es decir, su eficacia pluridireccional; de forma que los derechos fundamentales también han de ser efica- 
ces (vinculantes, de obligado respeto) en las relaciones entre sujetos privados que no podrán sustraerse a la eficacia aplicativa de los mismos. Los derechos fundamentales del trabajador, como derechos públicos subjetivos perfectos que son, deben ser respetados y pueden esgrimirse igualmente frente al empresario y en el contexto de la organización productiva empresarial así como frente cualquier tercero como son los compañeros de trabajo o, incluso, los clientes de la empresa ${ }^{3}$. Los principios de supremacía, eficacia y efecto útil de los derechos fundamentales, indisolubles de estos en razón de su centralidad jurídico-constitucional, obligan a que tengan validez aplicativa en cualquier contexto y relación jurídica que su titular entable. Mucho más cuando, como se ha ejemplificado antes, se trata de relaciones jurídicas, como la laboral, en las que, debido a la diferente posición jurídica de las partes y a la contradicción esencial de los intereses implicados, los derechos fundamentales pueden sufrir un mayor número de agresiones y limitaciones. Incluso, no infrecuentemente, superiores y de más intensidad que las que proceden de los poderes públicos debido a la mayor incisividad y carga limitativa que, paradójicamente, caracterizan la satisfacción del interés privado contrastante con el derecho fundamental del trabajador respecto de un más difuso interés general o público. Negar esta eficacia horizontal, pues, supondría poner en cuestión el propio derecho. Por eso la STC 98/2000, de 10 de abril, recalca, entre otras muchas (por ejemplo las Sentencias 170/1987, de 30 de octubre y 6/1988, de 21 de enero), la:

“plena efectividad de los derechos fundamentales del trabajador en el marco de la relación laboral, ya que esta no puede implicar en modo alguno la privación de tales derechos para quienes prestan servicio en las organizaciones productivas, que no son ajenas a los principios y derechos constitucionales que informan el sistema de relaciones laborales".

\section{LA EFICACIA RELATIVA DE LOS DERECHOS FUNDAMENTALES}

DEL TRABAJADOR: LOS LÍMITES INTERNOS DEL DERECHO FUNDAMENTAL Y LA AUSENCIA DE JERARQUÍA ENTRE LOS DERECHOS FUNDAMENTALES DEL TRABAJADOR Y EL INTERÉS DE LA EMPRESA

La afirmada eficacia horizontal de los derechos fundamentales del trabajador, y la posibilidad de su ejercicio en el contexto de la organización productiva empresarial, en la medida en que contrasta con otros principios, intereses y valores también constitucionalmente protegidos como los que se condensan en la expresión de "interés de la empresa", no puede ser absoluta, ilimitada, total e incondicionada, so pena de establecer una subordinación plena, que la norma constitucional no contempla (salvo, obviamente, en el supuesto del derecho a la vida), del interés empresarial al del trabajador en el ejercicio de su derecho fundamental. Así lo ha afirmado, también de manera muy frecuente y repetitiva, el TC siendo una expresión de ello las Sentencias 57/1994, de 8 de febrero, 143/1994, de 9 de mayo y 98/2000, de 10 de abril, según las cuales ningún derecho fundamental es absoluto, "pudien-

\footnotetext{
3 Bilbao Ubillos, J.M. La eficacia de los derechos fundamentales frente a particulares. Madrid, España: Centro de Estudios Políticos y Constitucionales, 1997.
} 
do ceder ante intereses constitucionalmente relevantes”. El rechazo del carácter absoluto de los derechos fundamentales tiene como consecuencia la afirmación de que:

"la efectividad de los derechos fundamentales del trabajador en el ámbito de las relaciones laborales debe ser compatible, por tanto, con el cuadro de límites recíprocos que pueden surgir entre aquellos y las facultades empresariales, las cuales son también expresión de derechos constitucionales reconocidos en los arts. 33 y 38 de la Constitución Española” (STC 196/2004, de 15 de noviembre).

De manera que la inserción del trabajador en una organización productiva ajena tiene la consecuencia inevitable de "modular aquellos derechos, en la medida estrictamente imprescindible para el correcto y ordenado desenvolvimiento de la actividad productiva, reflejo, a su vez, de derechos que han recibido consagración en el texto de la norma constitucional" (STC 99/1994, de 11 de abril), haciendo que "manifestaciones del ejercicio de aquellos que en otro contexto serían legítimas, no lo son cuando su ejercicio se valora en el marco de la relación laboral" (STC 126/1990, de 5 de julio).

La eficacia relativa de los derechos fundamentales del trabajador se manifiesta en el uso habitual, en el plano argumental, de términos y expresiones como las de "necesaria modalización del ejercicio de los derechos fundamentales del trabajador en cuanto a su ejercicio dentro de la empresa"; la "inevitable adaptación del ejercicio del derecho fundamental al contexto productivo en el que se ejercitan"; la "limitación necesaria de tales derechos en función de la satisfacción de los encontrados intereses empresariales"; las "inevitables restricciones de su ejercicio"; la "compatibilidad de los derechos fundamentales con la satisfacción del interés de la empresa"; o "la necesaria búsqueda del equilibrio entre derechos, libertades o valores constitucionales en conflicto". Todo ello conduce inevitablemente al resultado de que la eficacia de esos derechos, también en una relación interprivados, puede no ser plena, absoluta o ilimitada sino, como se ha indicado, relativa. Otra cosa es, y mucho más problemática, de qué forma se establece, en cada caso, el alcance de esos derechos fundamentales teniendo en consideración también el interés de la empresa; o, visto desde la perspectiva contraria, hasta qué punto y de qué forma pueden limitarse esos derechos en beneficio del interés empresarial. Para lo que las opciones metodológicas tienen, como ahora se verá, una trascendencia fundamental.

La forma habitual de afrontar los conflictos entre principios, derechos o valores es mediante la aplicación del principio de proporcionalidad, siendo una condición esencial el que ambos, como sucede en el caso, encuentren protección constitucional expresa. Como es conocido, el juicio general de proporcionalidad recurre a tres subcriterios, habitualmente manejados por la jurisprudencia constitucional, cuales son los de necesidad, idoneidad y de proporcionalidad en sentido estricto. Sin embargo, antes de exponer el contenido y la función concreta de este tipo de criterios, es preciso detenerse en dos cuestiones previas que condicionan fuertemente el juicio de constitucionalidad, y no precisamente en beneficio del trabajador, dependiendo, de una parte, de la perspectiva desde la que se enfoque el conflicto $y$, de otra parte, del rechazo a establecer una preferencia o jerarquía entre los derechos o intereses implicados. 
En este sentido, el tratamiento de la colisión entre los derechos fundamentales del trabajador y el interés de la empresa es diferente según que la iniciativa del ejercicio del derecho fundamental parta del trabajador reclamando de la organización empresarial el deber de soportarlo o si, por el contrario, se trata de una hipótesis en la que la iniciativa limitadora procede del empresario al pretender imponer (o prohibir) al trabajador comportamientos que constituyen una limitación del ejercicio normal de sus derechos fundamentales. Unos ejemplos servirán para diferenciar ambas posiciones.

En el primer caso se trataría de un trabajador que, por ejemplo, pretende decidir sobre su aspecto físico en el desarrollo de su actividad profesional exigiendo de la empresa el respeto a esa elección en cuanto manifestación del derecho fundamental a la propia imagen, o que reclama la posibilidad de ejercitar su libertad religiosa con prácticas de esta naturaleza durante la jornada laboral o al menos compatibles con ella, o que exige de la empresa el respeto a su libertad de información o de expresión sobre temas relacionados con la misma reivindicando el derecho a manifestarse libremente. Son casos en los que podría decirse que la posición del trabajador es activa, correspondiendo a él la iniciativa que provoca el conflicto mientras que la empresa queda correlativamente obligada, en una posición pasiva, a soportar las consecuencias de ese ejercicio en relación con el funcionamiento del proceso productivo, con su imagen o con sus intereses económicos, que puedan quedar afectados por ese ejercicio del derecho fundamental por parte del trabajador.

En el segundo caso, en cambio, es el empresario el que, haciendo uso de sus poderes empresariales exige (o prohíbe) a los trabajadores una determinada conducta que incide, limitándolo, sobre algún derecho fundamental. Aquí la posición activa es la de la empresa, reclamando del trabajador, en una situación pasiva, el soportar los recortes de su derecho fundamental. Los ejemplos son claros, numerosos y frecuentes: exigencia de someterse a determinados reconocimientos médicos siempre invasivos de la intimidad personal; imposición de un concreto uniforme de trabajo o prohibición de ciertos atuendos y adornos personales; limitación de los derechos de información o expresión de los representantes de los trabajadores con el pretexto del carácter confidencial o reservado de las informaciones proporcionadas o para salvaguardar la imagen de la empresa; establecimiento de formas de control de la actividad laboral mediante la grabación de conversaciones privadas e imágenes; uso de datos reservados o íntimos para una finalidad distinta para la que han sido obtenidos así como su tratamiento informático sin el consentimiento y/o conocimiento del trabajador; registro de taquillas, objetos personales y ordenadores; designación de ciertos trabajadores para que desempeñen el trabajo, por motivos de seguridad, en los casos de huelga; exigencia de identificación previa a la huelga de los trabajadores huelguistas para proceder a adoptar las medidas organizativas necesarias para paliar su impacto, etc.

Pues bien, cuando la posición del trabajador es activa, y previamente a considerar la potencialidad limitativa de los intereses empresariales sobre el derecho fundamental que se pretende ejercitar, el juicio atiende al criterio del correcto ejercicio del derecho fundamental haciendo recurso a los que se denominan límites internos del derecho que operan de forma autónoma y al margen de su contraste con los intereses de la empresa. Así, se considera que el ejercicio activo del derecho fundamental por parte del trabajador debe realizarse de conformidad con ciertos parámetros que determinan, de forma autónoma, la legitimidad o 
ilegitimidad de dicho ejercicio y que se concretan en la exigencia del respeto a los principios de buena fe y ejercicio no abusivo del derecho, entendidos no en un sentido contractual (porque entonces principios meramente contractuales estarían delimitando un derecho constitucional) sino como exigencias internas del propio derecho fundamental para poder calificar su ejercicio como adecuado a la función constitucional del propio derecho. De forma que la pretensión del trabajador será inicialmente merecedora de tutela en la medida en que se haga un uso adecuado, o no abusivo, del derecho en el sentido de que se ejercite de conformidad con la correcta finalidad del mismo. El ejemplo más claro es el de las libertades de información y de expresión sometidas, en el primer caso, a las exigencias de la veracidad, aunque sea entendida no solo en el sentido de que la información que se transmite sea realmente cierta sino en el más flexible de que el informante haya desplegado la diligencia necesaria de comprobación de la realidad de lo que se informa; y, por lo que hace a la libertad de expresión, en cuanto manifestación de opiniones y juicios, que se trate de expresiones que no sean gratuitamente degradatorias o insultantes. Y, de no superar esas exigencias, el ejercicio del derecho deberá entenderse como abusivo sin necesidad ya de contrastarlo, buscando el punto de equilibrio, con las exigencias derivadas del interés de la empresa; haciendo innecesario, por tanto, el juicio de proporcionalidad. Se trata de los que se suelen calificar como los cánones de ejercicio del derecho fundamental que determinan el recurso legítimo al mismo.

Algo semejante sucede con otros derechos fundamentales como es el caso del derecho de huelga en relación con el cual se considera abusivo el recurso a medios de presión colectiva que pretenden disfrazarse bajo otra apariencia que, sin suponer un coste para el trabajador huelguista (el respeto de los requisitos formales y procedimentales establecidos para dicho ejercicio y la pérdida del salario por la realización de la huelga), producen el mismo efecto; como acontece con las bajas colectivas por enfermedad coincidentes temporalmente de forma voluntaria y concertada. Se trataría, en realidad, de un recurso fraudulento a un mecanismo de exoneración de la obligación laboral, la baja laboral, utilizándolo con una finalidad distinta de la que el ordenamiento se asigna, el conseguir la ausencia simultánea al trabajo de un amplio número de trabajadores con un efecto de alteración de la normalidad laboral similar a la de la huelga. Un nuevo ejemplo, pues, de un uso abusivo o fraudulento de un derecho fundamental que hace innecesario el juicio de proporcionalidad. En un sentido similar puede traerse a colación el derecho fundamental a un trato igual que solo estará fundamentado si el elemento de comparación es homologable y no existe una justificación razonable de la diferencia, sin que sea necesario proceder a la búsqueda del equilibrio entre el derecho fundamental y el interés de la empresa ya que el conflicto queda previamente resuelto al considerar si el trato igual que se reclama de la empresa se apoya en los dos factores de situación comparable y falta de justificación de las diferencia.

Cuando, por el contrario, la iniciativa, en este caso limitativa del derecho fundamental, procede del empresario (lo que es, por otra parte, el tipo de conflicto más habitual entre derechos fundamentales e interés de la empresa), no existe un juicio paralelo previo y autónomo de la propia legitimidad de la limitación. La razón es clara y está relacionada con la propia indefinición del interés de la empresa al cual puede referirse una amplísima gama de decisiones empresariales las cuales, en general, quedan en sí mismas habilitadas con el 
simple hecho de ser expresión de algunos de los poderes empresariales que constituyen el instrumento de plasmación y de defensa del interés de la empresa. De forma que, previamente al juicio de proporcionalidad, no existe ningún filtro a esas decisiones como sí sucede con los derechos fundamentales del trabajador, mucho más delimitados en su contenido que ese genérico interés de la empresa. Con lo que el comportamiento activo de la empresa, limitador del derecho fundamental, está dotado de una mayor eficacia inicial al carecer de límites internos (salvo los muy obvios de la habilitación legal para imponer las limitaciones y de que esta estén establecidas por quien tiene la facultad de hacerlo) y al imponérsele restricciones solo desde fuera y siempre que estén cumplidamente justificadas, ahora sí sobre la base del derecho fundamental; lo que sitúa ya en el terreno de la aplicación del juicio de proporcionalidad.

Se pasa así, en cuanto al interés empresarial, de la necesaria justificación del derecho (característica del ejercicio del derecho fundamental) a la exigencia de fundamentación de los límites externos al mismo ya que, ab initio, la posición activa del empresario está más tutelada puesto que su justificación suficiente se basa, apriorística e incondicionadamente, en el propio interés empresarial, mientras que descarga argumentalmente sobre la posición pasiva del trabajador el esfuerzo de justificar las limitaciones que se quieren imponer a la libertad de empresa, atribuyéndose prioridad al interés empresarial que queda sometido solo a la condición de que las limitaciones de los derechos fundamentales del trabajador que de él se derivan sean adecuadas, necesarias o imprescindibles y proporcionales. Se trata de un planteamiento que, al afectar al curso argumental de la limitación recíproca o del equilibrio entre derechos, produce un efecto práctico de preferencia del interés de la empresa que se ejercita de forma activa sobre el derecho fundamental que soporta pasivamente ese ejercicio. Como se ha dichó ${ }^{4}$ :

"La potencialidad restrictiva de este planteamiento resulta, por lo demás, particularmente intensa si se tiene en cuenta que la libertad de empresa, que actúa en principio como soporte constitucional de las pretensiones empresariales, es un derecho de gran amplitud, en la medida en que abarca, entre otras, las libertades de desenvolver una actividad económica, tomar las decisiones relacionadas con su desarrollo y competir en un mercado libre"; añadiendo, lo que es más relevante, que "prácticamente cualquier decisión empresarial pueda ser reconducida a su ejercicio, configurándole legitimidad prima facie desde el punto de vista constitucional".

Lo que no sucede, como se ha dicho, con los derechos fundamentales. De forma que es el valor del interés empresarial el que se sitúa, de partida, en una situación de preeminencia a través de una jerarquización, práctica aunque no formal, que desvirtúa, desde el principio, el alcance del derecho fundamental que se pretende limitar por la empresa, llevando la atención del intérprete más al análisis del fundamento de la limitación del derecho fundamental y a las razones que pueda esgrimir el trabajador para oponerse a la misma más

4 SAnguinetTi Raymond, W. "Derechos fundamentales de la persona del trabajador y poderes empresariales”, en: Relaciones Laborales, 21-22/2012, España, p. 22. 
que a la tutela del propio derecho. Dicho de otra forma, no se parte de la defensa y la potenciación del derecho fundamental sino de la posible justificación de los límites al mismo; lo que, como se ha dicho, coloca al interés de la empresa en una posición preferente.

La otra cuestión previa es la relativa a la jerarquización de los derechos o intereses que gozan de tutela constitucional. Es cierto que esa jerarquía no puede derivarse de la ubicación del derecho o interés en el texto constitucional (el llamado criterio topográfico) y ni siquiera de que unos derechos estén más protegidos que otros mediante procedimientos especiales o reglas procesales específicas de garantía. Pero es indudable que el valor constitucional de unos y de otros es diverso en la medida en que unos, los derechos fundamentales del trabajador, se conectan con el valor superior de la dignidad personal, predicándose de ellos la naturaleza de inviolables y siendo la expresión del libre desarrollo de la personalidad, mientras que la libertad de empresa tiene un vínculo más indirecto con esos valores personales ya que predomina en la misma su contenido económico y se reconoce en función de la satisfacción de intereses organizativos y productivos. Así lo ha afirmado alguna vez el TC (STC 186/2000, de 10 de julio) declarando la posición preeminente de los derechos fundamentales. De esta diferencia quizás debiera derivarse necesariamente, si no una superior jerarquía de estos, al menos una preferencia funcional que exigiría una satisfacción prioritaria. De forma que el objetivo debería ser la máxima garantía de los derechos fundamentales frente al interés de la empresa que solo podría tutelarse en perjuicio del derecho fundamental cuando quedara garantizada la satisfacción de aquel con el mayor alcance posible, restando a la libertad de empresa el espacio de ejercicio que fuera compatible con la mayor tutela, derivada de su contenido y de su función, del derecho fundamental de que se trate. No obstante, la exclusión de toda jerarquía formal entre los derechos o intereses enfrentados excluye esa preferencia funcional unilateral del derecho fundamental para aceptar, en cambio, una preferencia aleatoria del derecho fundamental sobre el interés de la empresa, o viceversa, según las circunstancias de cada caso, de cada derecho y de cada limitación impuesta al mismo.

\section{EL PRINCIPIO DE PROPORCIONALIDAD EN SENTIDO AMPLIO: SUS DEFICIENCIAS EN LA BÚSQUEDA DEL EQUILIBRIO ENTRE LOS DERECHOS FUNDAMENTALES DEL TRABAJADOR Y LA LIBERTAD DE EMPRESA}

Se ha señalado antes que el principio o juicio de proporcionalidad general está integrado por tres subcriterios como son los de: a) de idoneidad o adecuación; b) de necesidad, indispensabilidad, imprescindibilidad o limitación mínima; y, c) de proporcionalidad en sentido estricto. Tales criterios se aplican a las limitaciones que el interés de la empresa impone al ejercicio de los derechos fundamentales determinando, caso de superar los tests, la legitimidad constitucional de tales límites y su respeto, compatible con la satisfacción del propio interés, del derecho fundamental afectado.

En cuanto al criterio de la idoneidad o de la adecuación consiste en analizar si la medida empresarial limitativa del derecho fundamental es susceptible de provocar el efecto que se propone (STC 66/1995, de 23 de mayo), en el sentido de que sea apta o adecuada para la 
protección del interés constitucional que entra en conflicto con el derecho fundamental que se limita; de manera que se valora si existe una correcta relación entre medios y fines o entre la limitación de un derecho y la tutela del interés empresarial contrastante; esto es, una conexión directa de utilidad. Toda limitación, pues, del derecho fundamental debe ser idónea, en el sentido de apta o adecuada, para alcanzar el fin, considerado constitucionalmente legítimo, que se persigue con ella de tutelar el interés empresarial en conflicto con el derecho fundamental (STC 200/1997, de 24 de noviembre), debiendo tener la medida limitativa la capacidad de garantizar el logro de la finalidad perseguida (STC 265/2000, de 13 de noviembre).

Un ejemplo podría ser el de los reconocimientos médicos impuestos por la empresa que, obviamente, lesionan la intimidad personal del trabajador; o la imposición de un uniforme sanitario a los trabajadores de los centros hospitalarios; o la obligación de los trabajadores encargados de la seguridad de seguir prestando su labor en el caso de huelga; o la prohibición del uso de los ordenadores de la empresa para comunicaciones de tipo personal; o la instalación de cámaras para supervisar la prestación laboral; o, en fin, el pago de retribuciones especiales a determinados trabajadores, superiores a las de otros de su misma categoría, dependiendo del momento de ingreso en la empresa. En relación con estos ejemplos, el criterio de la idoneidad solo juzga la constitucionalidad de la medida desde el punto de vista de su directa funcionalidad para lograr el fin previsto, cuya legitimidad en sí mismo no se pone en cuestión y que, en todo caso, resulta avalada por la amplitud constitucional del reconocimiento de la libertad de empresa.

De esta forma, los reconocimientos médicos son idóneos porque constituyen un instrumento para preservar la salud laboral del propio trabajador o de terceros (compañeros de trabajo, usuarios); el uniforme laboral es adecuado por razones de identificación y de higiene particularmente importante en un centro sanitario; la obligación del personal de seguridad de trabajar durante la huelga es idónea para garantizar la seguridad de bienes y personas de la empresa; la prohibición del uso personal de los ordenadores de la empresa se relaciona con el destino productivo lógico de las herramientas puestas a disposición de los trabajadores y para mejorar la productividad del trabajo; las cámaras en los lugares de trabajo son una forma muy eficiente de controlar la normalidad del trabajo y la aplicación del trabajador al mismo; las retribuciones superiores a los trabajadores ingresados en la empresa antes de una fecha por contraste con la de los ingresados con posterioridad está directamente relacionada y es apta la reducir los costes salariales. Los ejemplos y las justificaciones pueden ser muy numerosos.

Sin embargo, como puede apreciarse, el juicio de idoneidad, que pretende ser un instrumento de fijación del punto de equilibrio entre derechos e intereses en conflicto, en realidad prescinde del derecho fundamental afectado, de su entidad y contenido, para centrar el análisis en las medidas limitativas propuestas. De este modo, el juicio de idoneidad lleva a excluir, en principio, solo aquellas medidas caprichosas, arbitrarias, irracionales, inefectivas, inútiles y carentes de una conexión sólida con el fin que se propone y cuya legitimidad ya es en sí misma, y sin necesidad de un análisis particularmente preciso, totalmente dudosa. Esto es, excluye solo los medios claramente no aptos para la realización del concreto interés empresarial interés en razón del cual han sido adoptados. Pero permite validar sin dificultad 
esas otras medidas de las que pueda declararse que existe una conexión razonable entre ellas y el fin propuesto.

Desde esta perspectiva, nadie discutirá que exigir un reconocimiento médico determinado al trabajador es indudablemente funcional al fin de seleccionar a los trabajadores más idóneos o aptos; o que prohibir el ejercicio de la libertad de expresión o de información en un sentido crítico para la empresa sirve para preservar su imagen pública ante la clientela; o que impedir la exteriorización de las convicciones religiosas mediante el uso por parte del trabajador de ciertas vestimentas también favorece la imagen de la empresa y evita el surgimiento de conflictos en el seno de la organización productiva; o, en fin, que cambiar de puesto de trabajo a la mujer que ha solicitado una jornada reducida por cuidado de hijos puede ser algo idóneo para mantener la productividad del puesto de trabajo afectado. En cuanto mero juicio de utilidad, la idoneidad puede acabar validando medidas que se justifican al margen del derecho fundamental afectado y que pueden ser enormemente agresivas para el mismo. El principio de adecuación o de idoneidad, pues, consiste en un juicio unilateral de la limitación impuesta al derecho fundamental que, partiendo de la relevancia constitucional y de la legitimidad del interés empresarial, se limita a indagar si es apta para atender a ese interés, de forma que cualquier limitación puede quedar justificada por el solo hecho de que sirva o sea precisa para satisfacer el interés empresarial. La potencialidad justificatoria de las restricciones del derecho fundamental que incorpora el criterio de la idoneidad es, en consecuencia, evidente y extraordinariamente amplia.

Algo semejante sucede con el juicio de necesidad. Concebido como un test de imprescindibilidad o de intervención mínima, se exige con él que la medida limitativa del derecho sea la menos incisiva de las posibles, siempre garantizando un nivel equivalente de eficacia que otras más agresivas o dañinas para el derecho fundamental. Identificado el fin, desde la perspectiva de la medida limitativa del derecho, se trata aquí de considerar si, de entre todas las medidas posibles de efecto equivalente, la elegida es la menos lesiva del derecho fundamental. La garantía del fin perseguido, un elemento también determinante del juicio de idoneidad, preside la argumentación; de manera que, tratándose de una medida idónea, solo deberá ceder ante otra medida que tenga una idoneidad equivalente. Si no es así, el juicio de indispensabilidad acaba siendo inoperante ya que, si no existe una medida alternativa dotada de estas características, la medida limitativa propuesta siempre será indispensable por única con su efectividad. Solo si esas otras alternativas existen, el juicio de indispensabilidad forzará a elegir entre ellas la que, con un efecto útil equivalente, suponga un menor sacrificio del derecho fundamental afectado o sea menos lesiva de este. El TC ha recurrido frecuentemente a este criterio afirmando que las restricciones del derecho fundamental deben ser las estrictamente indispensables (STC 66/1991, de 22 de marzo) o imprescindibles para garantizar los intereses y bienes constitucionales que justifican su implantación (STC 113/1989, de 22 de junio). Pero debe quedar claro que la opción por una alternativa menos dañosa o lesiva del derecho o que suponga un menor sacrificio del mismo (STC 19/1988, de 16 de enero; STC 178/1989, de 2 de noviembre) no será la preferida en cualquier caso; esto es, no hay una opción autónoma por la menor lesión, sino solo si, pese a esa menor agresividad, su eficacia en relación con el interés empresarial es semejante a la de la medida más restrictiva del derecho. Lo que, con mucha frecuencia, conduce a la con- 
clusión de que la medida limitativa es, con su grado de eficacia o idoneidad, la única posible.

Un ejemplo de las consecuencias prácticas, en el sentido dicho, de los dos criterios anteriores puede apreciarse en la STC 66/1995, de 8 de mayo, en relación con la convocatoria, a las 13.00 horas de un viernes, por parte de un sindicato de una concentración en una plaza pública del centro de Madrid, de dos horas y media de duración, en apoyo a la negociación del convenio colectivo de la banca privada. La concentración fue prohibida por la autoridad gubernativa debido a que la dicha plaza pública era una zona de elevadísima intensidad media de circulación de vehículos debido a su ubicación y a la realización de obras en calles adyacentes, lo que provocaría un colapso total del tráfico que afectaría tanto a la propia plaza elegida como lugar de la concentración como a otras vías de circulación cercanas que se consideraban ejes circulatorios esenciales en la medida en que concentraban una importante cantidad de vehículos de transporte, tanto públicos como privados. En definitiva, la prohibición se basaba en la gravísima incidencia de la concentración y de la marcha convocada en el tráfico y en el orden público ciudadano al afectar igualmente al tránsito de servicios públicos básicos (policía, bomberos, ambulancias). Contra esta resolución de la autoridad pública, el sindicato convocante se alzó mediante los pertinentes recursos ordinarios y finalmente a través del recurso de amparo considerando que la misma vulneraba el derecho fundamental de reunión recogido en el art. 21 de la Constitución española. Pues bien, el TC estimó que la medida gubernativa de prohibición de la concentración no atentaba al derecho fundamental de reunión al superar los tests de idoneidad y necesidad, sin necesidad práctica de referirse al principio de proporcionalidad en sentido estricto, al cual recurrió de manera puramente formal y sin contenido.

En primer lugar, considerando que la prohibición de la reunión era una medida idónea para tutelar otros intereses en conflicto, en el caso el orden y la seguridad pública, solo a partir de una argumentación genérica acerca de que este tipo de reuniones en determinadas vías públicas tienen importantes repercusiones sobre la normalidad del tráfico (algo, desde luego, obvio) y que también pueden incidir en la seguridad ciudadana al afectar, por hipótesis, a la normal prestación de determinados servicios públicos como los de policía, bomberos o de transporte sanitario. Y ello pese a que la propia Sentencia acepta que este tipo de reuniones o concentraciones, en la medida en que buscan dar la mayor publicidad a determinados conflictos laborales, inevitablemente han de convocarse, si quieren ser eficaces, en lugares de particular densidad de tráfico de vehículos y personas, mucho más cuando en el entorno del lugar se concentraban numerosas sedes de las entidades bancarias afectadas por el conflicto colectivo, afirmando además que la vía pública no es solo un espacio de tránsito y de circulación sino también de participación ciudadana. No obstante, en relación con la idoneidad, el TC concluyó, de forma muy lacónica que es claro que "la prohibición de la celebración de la concentración permite alcanzar el fin perseguido cual es la protección del orden público y de la integridad de bienes y personas". Algo obvio ya que cualquier prohibición, al excluir el impacto sobre los bienes públicos reseñados, siempre los garantiza más eficazmente que la autorización de la reunión; y ello al margen, porque en el juicio de idoneidad no se plantea, del grave perjuicio que la prohibición supone al ejercicio del derecho fundamental de reunión. 
En cuanto al juicio de necesidad, esto es "si la prohibición total del ejercicio del derecho resultaba imprescindible o cabía la adopción de medidas menos drásticas e igualmente eficaces para la consecución del fin perseguido", el TC resuelve también en sentido positivo alegando que, como los propios convocantes habían manifestado, cualquier otra posibilidad de celebrar la concentración (otro día, otro lugar, otra hora) hubiera desvirtuado el objetivo perseguido por quienes pretendían ejercitar el derecho de reunión. Puesto que no existían otras alternativas menos gravosas para el derecho ya que las posibles significaban en la práctica negar el ejercicio mismo del derecho de reunión por ineficiente para los fines propuestos, la conclusión del TC fue que, no existiendo alternativas igualmente eficaces para preservar el interés público a proteger, la medida debía considerarse igualmente necesaria. Sin que la Sentencia se ocupara especialmente, una vez superados los dos tests iniciales, del juicio de proporcionalidad en sentido estricto. Esta Sentencia, al atender prioritariamente al interés protegido por la medida limitativa, acabó avalando prácticamente cualquier limitación del derecho fundamental, incluso la más restrictiva de la prohibición de su ejercicio. $\mathrm{O}$, cuando menos, incidiendo poderosamente, con un resultado predecible, sobre el juicio de proporcionalidad en sentido estricto que, finalmente, se revela como ineficiente o inútil. Es justamente este resultado de la aplicación de los criterios de adecuación y de necesidad el que lleva a potenciar, en defensa del derecho fundamental, la sustitución del principio general de proporcionalidad en sentido general por el juicio de proporcionalidad en sentido estricto o de ponderación, como criterio central para la solución de los conflictos entre los derechos fundamentales del trabajador y la libertad de empresa.

Más recientemente, el TC (STC 186/2000, de 10 de julio) ha abordado, con argumentos y resultados semejantes, la confrontación entre el derecho fundamental a la intimidad y el interés de la empresa en controlar el trabajo desarrollado por los trabajadores instalando un circuito cerrado de televisión que enfocaba a algunos puestos de trabajo. Frente a los argumentos del trabajador en el sentido de que ese mecanismo de control lesionaba su derecho a la intimidad ya que, además de controlar el trabajo, esas instalaciones registran otros actos que pertenecen a su intimidad ya que el control no es selectivo en cuanto a las imágenes que capta (un argumento fundamentalmente referido al criterio de la necesidad y de la proporcionalidad en sentido estricto), la respuesta del TC ha sido la siguiente:

De una parte, afirmando que:

"el poder de dirección del empresario, imprescindible para la buena marcha de la organización productiva (organización que refleja otros derechos reconocidos constitucionalmente en los arts. 33 y $38 \mathrm{CE}$ ) (...) atribuye al empresario, entre otras facultades, la de adoptar las medidas que estime más oportunas de vigilancia y control para verificar el cumplimiento del trabajador de sus obligaciones laborales”.

Si bien siempre y cuando se respete la dignidad y la intimidad del trabajador y, de quedar de alguna manera afectada, aplicando, para validar los comportamientos empresariales, el juicio de proporcionalidad. De otra, sosteniendo que la medida empresarial queda justificada (ya que existían sospechas razonables de que el trabajador había cometido graves irregularidades en su puesto de trabajo), que es la idónea para la finalidad perseguida (com- 
probar si efectivamente el trabajador cometía las mencionadas irregularidades con el fin de adoptar las pertinentes medidas disciplinarias), necesaria (al no existir otra medida menos agresiva para la intimidad personal para comprobar la comisión de las irregularidades y para obtener una prueba de las mismas) y, finalmente proporcionada (por cuanto la grabación se limita a una zona concreta y con una duración temporal limitada hasta la constatación del comportamiento ilícito del trabajador). En realidad, el TC maneja en exclusiva, e incluso de forma discutible, los criterios de adecuación y de necesidad ya que el alegado de la proporcionalidad en realidad no expresa sino una idea de intervención mínima (por zona de grabación y por duración). Como ahora se verá, la proporcionalidad en sentido estricto introduce una relación entre sacrificio del derecho fundamental y ventajas para el interés general (de la empresa); lo que no se valora en la Sentencia ya que la grabación se hace sin advertir de ello al trabajador. Por ello el sacrificio de su intimidad es mucho mayor (por cuanto el trabajador ignora la existencia del circuito cerrado lo que hace que se graben comportamientos personales sin relación con el asunto central y que sin duda pertenecen a la intimidad personal) que la ventaja que la empresa obtiene y que, si bien se advierte, no se centra en la eliminación de los comportamientos irregulares (lo que podría haber hecho con otros medios de control menos agresivos o haciendo pública la instalación del sistema de grabación), sino en la sanción de la conducta irregular, algo de menor trascendencia para el funcionamiento de la empresa. En definitiva, el TC valida la conducta empresarial por idónea y necesaria para una finalidad cuya relevancia no juzga (la sanción del trabajador) y respecto de la cual no aplica sino formalmente el juicio de proporcionalidad en sentido estricto, bastando para validar el comportamiento empresarial los otros dos juicios de adecuación y de necesidad.

\section{EL PRINCIPIO DE PROPORCIONALIDAD EN SENTIDO ESTRICTO O JUICIO DE PONDERACIÓN}

La aplicación del juicio de proporcionalidad en sentido amplio, como se ha visto, dando prioridad a los criterios de adecuación y de necesidad sobre el de proporcionalidad en sentido estricto, ha producido resultados discutibles desde el punto de vista de la protección de los derechos fundamentales frente a los intereses de la empresa. Seguramente porque los criterios de adecuación y de necesidad no tienen tanto en cuenta el derecho fundamental afectado sino que miran a la legitimación de las decisiones empresariales, a priori dotadas de validez, como instrumentos de tutela de los intereses de la empresa. Por eso el juicio de proporcionalidad en sentido estricto, en el que tiene ya entrada el derecho fundamental en pie de comparación con la libertad de empresa, queda habitualmente desplazado o utilizado de forma retórica o formal. A este efecto se ha sostenido que el principio de proporcionalidad en sentido amplio (con el protagonismo de la adecuación y de la necesidad) solo debe ser aplicable en situaciones en las que entre los intereses en conflicto existen unos predominantes, como sucede cuando la confrontación tiene lugar entre el derecho fundamental individual y los intereses y fines públicos protegidos constitucionalmente. Trasladarlo a las relaciones entre privados tiene como consecuencia lo que se ha venido viendo en este trabajo y que no es otra cosa que una preferencia práctica del interés empresarial sobre el derecho fundamental del trabajador, asimilando la posición de la empresa a la del poder público y 
planteando la relación del trabajador con ella en los mismos términos de inferioridad del derecho fundamental. De manera que el criterio a aplicar en relación con el conflicto entre derechos del trabajador e interés de la empresa es el adecuado para una relación entre privados y que no es otro que el principio de proporcionalidad en sentido estricto o juicio de ponderación ${ }^{5}$.

El juicio de proporcionalidad en sentido estricto consiste en la ponderación de los intereses en conflicto y persigue determinar el que debe ser prioritario en el caso concreto. Una ponderación que, como afirma la STC 186/2000, de 10 de julio, consiste en constatar que la medida restrictiva de un derecho fundamental es equilibrada, por derivarse de ella más ventajas o beneficios para el interés empresarial a proteger y para el interés general de la colectividad que perjuicios sobre el derecho fundamental afectado; o, dicho de otra forma, que los instrumentos implantados por el empresario, aunque limitativos del derecho fundamental del trabajador, guardan una relación razonable con el fin que se persigue, de forma que el sacrificio impuesto al derecho fundamental sea proporcional a los beneficios que el empresario obtiene de la limitación del derecho. De manera que un sacrificio se considerará excesivo si su entidad no queda suficiente, razonable y proporcionalmente compensada con el beneficio que se deriva de la limitación impuesta. La proporcionalidad en sentido estricto expresa, pues, un equilibrio cuantitativo y cualitativo entre sacrificios y ventajas, como lo manifiesta la STC 98/2000, de 10 de abril, la cual, en relación con la pretensión de la empresa de instalar un sistema de grabación de las conversaciones de los trabajadores de un casino, existiendo ya un circuito cerrado de televisión para grabar las imágenes de los trabajadores de las mesas de juego mientras desarrollan su actividad, consideró la medida desproporcionada en cuanto que la finalidad perseguida, cual era garantizar la seguridad ante posibles reclamaciones de los clientes, suponía un plus de sacrificio excesivo del derecho a la intimidad de los trabajadores ya afectada por la grabación a través del circuito cerrado de televisión, lesionando de forma desproporcionada la intimidad de los trabajadores e incluso de los clientes. En definitiva, el criterio de proporcionalidad en sentido estricto se traduce en una relación coste/beneficio o de medios/fines que debe ser equilibrada, suponiendo "más ventajas o beneficios para el interés general que perjuicios sobre otros bienes o valores en conflicto" (STC 26/1981, de 17 de julio).

Cuando se define el principio de proporcionalidad en sentido estricto se suele recurrir al término "ponderación" como si fueran conceptos sinónimos o equivalentes ${ }^{6}$. Entendida la ponderación como el cálculo del peso relativo de dos entidades, es cierto que en el juicio de proporcionalidad en sentido estricto existe una ponderación, si bien limitada a la comparación entre sacrificios (para el derecho fundamental) y ventajas (para el interés empresarial) sin que en ese análisis se proceda a establecer el peso respectivo global del derecho fundamental y del interés empresarial, lo que constituiría el auténtico juicio de ponderación. Desde este punto de vista, y aunque es cierto que en la aplicación del principio de proporcionalidad existe la ponderación, el principio de ponderación es una técnica especí-

5 Rodríguez de Santiago, J.M. La ponderación de bienes e intereses en el Derecho Administrativo. Madrid, España: Marcial Pons, 2000, pp. 26 y 105 y ss.

6 Carrizosa Prieto, E. "El principio de proporcionalidad en el Derecho del Trabajo", en: Revista Española de Derecho del Trabajo, 123/2004, España, p. 495. 
fica que remite a una metodología propia y específica que se basa en la identificación de los principios, intereses y valores en juego, en la identificación del peso, entidad y relevancia de cada uno de ellos, y en la búsqueda del equilibrio adecuado entre los mismos a partir de la necesaria fijación de la preminencia de uno sobre otro. Como acertadamente ha señalado la STC 219/1992, de 3 de diciembre, se trata de la labor de determinar "el contenido de cada uno de los derechos en presencia y los límites externos que se derivan de su interacción recíproca”.

Dada la regulación constitucional, tanto de los derechos fundamentales como de la libertad de empresa, puede afirmarse que, más que normas en sentido ordinario, se trata de reglas jurídicas que tienen una enorme carga valorativa, incorporando principios fundamentales. Si es así, es claro que, dada la relevancia constitucional de ambos, no puede tener lugar un sacrificio pleno de uno en beneficio de otro, entre otras cosas porque no existe una clara prioridad o preferencia. Es lo que lleva a la que se ha denominado antes como eficacia relativa de los derechos fundamentales (y también del interés de la empresa, hay que añadir) que consiste en que la preeminencia de uno sobre otro no está fijada de manera apriorística sino que depende de las circunstancias de cada caso. El juicio de ponderación persigue justamente determinar esa precedencia en lo concreto sopesando, a través de una técnica comparativa, el valor circunstancial de cada uno.

Varios son los pasos argumentales que es preciso seguir. En primer lugar, el punto de partida no puede ser otro que estimar que la defensa del derecho fundamental del trabajador tiene un valor y una legitimidad al menos igual al de la libertad de empresa, de forma que, en el contexto de una relación privada como la laboral, todos los intereses en juego han de disfrutar de una protección al menos inicialmente equivalente, estando orientados ambos principios (el derecho fundamental, la libertad de empresa) a su máxima satisfacción en una lógica de optimización. Es la fase de la que podría calificarse como de comparación estática de los derechos, intereses o principios contrapuestos. Sin embargo, esta afirmación en paralelo del mismo valor de los principios o derechos deja de ser operativa cuando, en una segunda fase, surge el conflicto concreto y real entre ambos, poniéndose de manifiesto que sus posibilidades de realización están determinadas precisamente por la realización de los principios opuestos, de manera que se hace necesario fijar en qué medida uno de ellos debe ceder partiendo de la base de la imposibilidad de una satisfacción simultánea plena de ambos. La tercera fase de la aplicación del juicio de ponderación consiste en el establecimiento del criterio general para deducir la preferencia de un derecho o interés sobre otro y que inevitablemente es un criterio relacional. Para fijar esa preferencia, el criterio utilizable es el de la relación entre satisfacción y sacrificio respectivo de los derechos en conflictos, de forma que un derecho debe prevalecer sobre otro cuando su satisfacción sea más valiosa o importante que la insatisfacción del contrario u opuesto; o, dicho de otra forma, cuando los beneficios que obtiene el titular del derecho fundamental al imponer limitaciones a otro derecho o interés son superiores, desde el punto de vista constitucional y de la naturaleza de los derechos implicados, a los sacrificios que soporta el principio, valor o derecho limitado. El criterio general de ponderación también puede formularse como que el grado, el nivel o la intensidad aceptable de limitación de un derecho fundamental depende de la importancia de la satisfacción del principio contrario por lo que mientras más valiosa sea esta última ma- 
yor potencialidad tiene de limitar el derecho opuesto. Llevado lo anterior al contraste entre el derecho fundamental del trabajador y la libertad de empresa ello significa que mientras más intensa sea la limitación del derecho fundamental mayor debe ser la importancia del interés empresarial que satisface y, al contrario, que mientras más significativo sea el recorte del interés de la empresa, más relevante debe ser la satisfacción del derecho fundamental del trabajador implicado en el conflicto o, si se quiere, más grave ha de ser, desde la perspectiva constitucional, el precio de no satisfacerlo.

Esta es la formulación general, como se ha dicho, del juicio de ponderación pero su aplicación práctica requiere de una ulterior fase en la que ha de valorarse en lo concreto el peso, la trascendencia y la entidad de cada uno de los derechos o intereses en conflicto, una valoración que ha de estar guiada por la relevancia que el derecho de que se trate tiene en la estructura, el fundamento y las bases constitucionales y en la lógica de los valores consagrados por la Constitución. Esta valoración ha de proceder, así, a fijar la importancia de cada derecho puesto en conexión con los valores constitucionales centrales de los que es expresión. De esta forma, derechos que se conectan con la dignidad personal, con los principios de democracia y participación y con la realización de la justicia material estarán dotados de un mayor peso específico que los que se relacionan con razones económicas aunque ligadas a la libertad individual aquí expresada en la libertad de empresa y de iniciativa económica privada. Esta valoración separada de los principios o derechos contrastantes es lo que se califica como "peso abstracto de cada derecho fundamental" 7 . Y supone que los derechos fundamentales de los trabajadores a integridad física, a la intimidad, al honor y a la propia imagen (vinculados a la dignidad de la persona y manifestaciones del respeto a la misma) y los derechos de libertad sindical, huelga así como las libertades ideológicas y de expresión e información (directamente relacionados con los principios de democracia y de participación) ostentan una entidad y un peso superior, en principio, a los intereses de la empresa y a las libertades y poderes que constituyen su instrumento.

Partiendo de esta preeminencia genérica, la siguiente fase de la aplicación del juicio de ponderación consiste en la etapa relacional, en la que los derechos, dotados ya de un peso específico diferenciado, entran en colisión, siendo imposible la satisfacción plena y simultánea de ambos. En esta situación, es claro que ambos derechos habrán de sufrir limitaciones recíprocas cuya entidad cualitativa y cuantitativa vendrá determinada por el criterio de ponderación. De forma que habrá de establecerse la intensidad de la limitación que cada derecho habrá de soportar teniendo en cuenta que, como se ha dicho ya, mientras más intensa sea la limitación de un derecho o interés, más relevante debe ser el grado de satisfacción del derecho contrastante o, si se quiere, mayor el sacrificio de este si no se atendiera a sus exigencias. Como ha señalado el TC en su Sentencia 320/1994, de 28 de noviembre:

"la solución al problema que plantea la colisión o encuentro entre derechos libertades fundamentales consistirá en otorgar la preferencia al respeto de uno de ellos, justamente aquel que lo merezca, tanto por su propia naturaleza como por las circunstancias concurrentes de su ejercicio. No se trata, sin embargo, de establecer jerarquías a

SANGUINETTI RAYMOND, W. op. cit. (n. 4), p. 25. 
priori, sino de conjugar, desde la situación jurídica creada, ambos derechos y libertades, ponderando, pesando cada uno de ellos, en su eficacia recíproca, para terminar decidiendo y dar preeminencia al que se ajuste más al sentido y finalidad que la Constitución señala, explícita o implícitamente".

Estas relaciones pueden formularse de la siguiente manera, siempre partiendo del mayor peso específico de los derechos fundamentales del trabajador frente a los intereses de la empresa. Recurriendo a una escala de afectación y de satisfacción del derecho y del interés que va desde el menor nivel o leve, hasta el de mayor grado o intenso, pasando, en sentido creciente, por los niveles de pequeño, medio y grande, podrían ser aceptables las limitaciones impuestas a los derechos fundamentales del trabajador si esa afectación es leve o pequeña y el grado de satisfacción del interés empresarial es media o alta; como también en el caso de que las restricciones al derecho fundamental fueran grandes pero la satisfacción del interés de la empresa intensa. Pero no lo serían, en cambio, si el sacrificio del derecho es grande o intenso y la satisfacción del interés vinculado a la empresa es solo leve o pequeña, como tampoco si el sacrificio del derecho es medio o pequeño y la satisfacción del interés solo leve. No se oculta que esas calificaciones tienen un relativo margen de indefinición así como que pueden darse casos en los que afectación del derecho y satisfacción del interés tengan un nivel muy semejante. Situaciones que pueden afrontarse de dos maneras. De una parte, dando prioridad al interés empresarial si su grado de afectación es igual al de sacrificio del derecho; lo que es inaceptable ya que supondría dar mayor peso específico a la libertad de empresa frente al derecho fundamental. De otra parte, lo que es más correcto, dando prevalencia al derecho fundamental en los casos de equivalencia de afectación y ventajas, debido a su mayor peso específico derivado de su inserción en el esquema constitucional en los términos que se han indicado antes.

\section{UN EJEMPLO DE APLICACIÓN DEL JUICIO DE PONDERACIÓN}

Se trata de la STC 163/2006, de 22 de mayo, que resuelve sobre la misma materia, aunque en sentido contrario, de la Sentencia antes comentada 66/1995, de 8 de mayo. En el caso, un sindicato comunica a la autoridad gubernativa competente su propósito de realizar una concentración ante el Ministerio de Administraciones Públicas y, posteriormente, una manifestación, a media mañana, ocupando calles y avenidas del centro de Madrid con la finalidad de protestar contra la situación de crisis del organismo público de empleo y el deterioro del servicio público. Dicha concentración y manifestación fue prohibida, autorizándose solo una concentración ante el Ministerio de Empleo ocupando exclusivamente una zona peatonal. Pese a las modificaciones propuestas por el sindicato convocante, acortando la duración de estos actos, alterando el recorrido de la manifestación, reduciendo el impacto en el desarrollo del tráfico rodado y peatonal y finalizando en una concentración en un espacio ajardinado, la autoridad gubernativa prohibió los actos convocados al amparo de los derechos de reunión y de manifestación, constitucionalmente consagrados.

El TC, aplicando el juicio de ponderación no obstante tratarse de un conflicto entre un sujeto privado y el poder público, procede, en primer lugar, a establecer el peso específico de cada uno de los derechos e intereses implicados. De esta forma señala que: 
"el derecho fundamental de reunión reconocido en el art. 21 CE (es) una manifestación colectiva de la libertad de expresión efectuada a través de una asociación transitoria de personas, que opera a modo de técnica instrumental puesta al servicio del intercambio o exposición de ideas, la defensa de intereses o la publicidad de problemas y reivindicaciones, y cuyos elementos configuradores son el subjetivo (agrupación de personas), el temporal (duración transitoria), el finalista (licitud de la finalidad) y el real y objetivo (lugar de celebración). El relieve fundamental que este derecho (cauce del principio democrático participativo) alcanza en sus dimensiones subjetiva y objetiva dentro de un Estado social y democrático de Derecho como el proclamado en la Constitución ha determinado, incluso, que para muchos grupos sociales este derecho sea en la práctica uno de los pocos medios de los que disponen para poder expresar públicamente sus ideas y reivindicaciones".

El TC atribuye un alto peso específico al derecho de reunión y de manifestación ya que, como se aprecia, lo considera una expresión central de los valores de democracia y participación en cuanto cauce de expresión ciudadana, de naturaleza colectiva, en la defensa de intereses colectivos, de grupo o del conjunto de los ciudadanos. Por otra parte, y en cuanto al principio contrastante, el orden público, el TC lo conceptúa no como equivalente en este caso al orden público general "sino al orden público sin más, al orden público con peligro para personas o bienes y esta situación de peligro", siendo no un elemento adjetivo "que simplemente modula o califica externamente un concepto previo de orden público, sino un elemento sustantivo que define el contenido de ese concepto"; añadiendo que, ese orden público con peligro para personas y bienes, a la luz de los principios del Estado social y democrático de Derecho consagrado por la Constitución, debe entenderse que "se refiere a una situación de hecho, el mantenimiento del orden en sentido material en lugares de tránsito público, no al orden como sinónimo de respeto a los principios y valores jurídicos y metajurídicos que están en la base de la convivencia social y son fundamento del orden social, económico y político”. El peso específico, pues, del valor orden público, tal y como restrictiva y fácticamente lo define en el caso, es relativo ya que no se conecta con el valor jurídico de orden público, constitucionalmente establecido, y que fundamenta valores tan relevantes como la convivencia y el orden social, económico y político.

Establecida la preferencia funcional del derecho de reunión y de manifestación frente al tipo de orden público que se quiere tutelar con la prohibición de esos actos colectivos, ello no significa necesariamente que el orden público así concebido deba ceder frente a los derechos fundamentales de reunión y de manifestación. Lo que dependerá del grado de sacrificio que se quiera imponer a los derechos fundamentales en relación con las ventajas que puedan operarse en beneficio del orden público.

Así, por parte del orden público, su afectación se materializa con una cierta entidad:

"si existen razones fundadas de que se producirá una situación de desorden material en el lugar de tránsito público afectado, entendiendo por tal desorden material el que impide el normal desarrollo de la convivencia ciudadana en aspectos que afectan a la integridad física o moral de personas o a la integridad de bienes públicos o privados. Estos son los dos elementos que configuran el concepto de orden público con peligro 
para personas y bienes consagrado en este precepto constitucional. Ciertamente, el normal funcionamiento de la vida colectiva, las pautas que ordenan el habitual discurrir de la convivencia social, puede verse alterado por múltiples factores, que a su vez pueden afectar a cuestiones o bienes tan diversos como la tranquilidad, la paz, la seguridad de los ciudadanos, el ejercicio de sus derechos o el normal funcionamiento de los servicios esenciales para el desarrollo de la vida ciudadana; sin embargo, solo podrá entenderse afectado el orden público al que se refiere el mentado precepto constitucional cuando el desorden externo en la calle ponga en peligro la integridad de personas o de bienes".

Seguridad de una afectación relevante al normal desarrollo de la convivencia ciudadana y peligro para la integridad física y moral de las personas o para la integridad de bienes públicos o privados, no entendido desde luego como sinónimo de violencia sobre las personas o las cosas por parte de los manifestantes, son los sacrificios que soportaría el orden público si se diera satisfacción plena al derecho fundamental de reunión y de manifestación. Rechaza a este respecto la STC 163/2006 que el orden público, en el sentido antes señalado, quede afectado por las “ concentraciones que afectan a la circulación de vehículos por las vías de tránsito público (ya que) lo primero que cabe afirmar es que solo en supuestos muy concretos podrá concluirse que la afectación del tráfico conlleva una alteración del orden público con peligro para personas o bienes", porque la concentración y la manifestación repercutan gravemente sobre el tráfico rodado y peatonal, dificultando el que se desenvuelva con la normalidad exigible así como la prestación de los servicios públicos de emergencia.

Por el contrario, en relación con los derechos de reunión y de manifestación, tienen como objeto "el intercambio y la comunicación pública de ideas y reivindicaciones", en conexión directa con las libertades de expresión y los principios de participación y democracia, añadiendo que:

"en una sociedad democrática, el espacio urbano no es solo un ámbito de circulación, sino también un espacio de participación" y recalcando que "en ciertos tipos de concentraciones el lugar de celebración es para los organizadores la condición necesaria para poder ejercer su derecho de reunión en lugares de tránsito público, puesto que del espacio físico en el que se desenvuelve la reunión depende que el mensaje que se quiere transmitir llegue directamente a sus destinatarios principales. Esto acontece, por ejemplo, en los supuestos en los que los reunidos pretenden hacer llegar sus opiniones o sus reivindicaciones, no solo a la opinión pública en general o a los medios de comunicación, sino muy particularmente a determinadas entidades o, mejor, a determinadas personas que ocupan cargos en las mismas. La posibilidad de realizar la concentración en un lugar próximo a la sede de las entidades afectadas y en un horario de trabajo se convierte, en estos casos, en factores determinantes a la hora de ejercer el derecho de reunión".

Para concluir "no es menos cierto que por su propia naturaleza el ejercicio de ese derecho requiere la utilización de los lugares de tránsito público y, dadas determinadas cir- 
cunstancias, permite la ocupación, por así decir, instrumental de las calzadas”. El peso específico de los derechos implicados se hace mayor si, además, se tiene en cuenta que el ejercicio de este tipo de derechos es, en muchos casos, la única vía de participación para muchos ciudadanos que es a través de ellos que expresan sus opiniones y proclaman sus peticiones, exigencias o reivindicaciones.

Establecido el mayor peso específico de los derechos fundamentales de reunión y de manifestación, la STC 163/2006 procede a determinar qué grado de restricciones podrían sufrir esos derechos que permitiera una mayor satisfacción del orden público potencialmente afectado. En este sentido se refiere a los cambios en horario, itinerario, lugar de concentración o duración que significan una afectación leve del derecho fundamental, siempre que este pueda seguir desempeñado eficazmente su función. Por el contrario, si, en virtud de la entidad de esos cambios, como es el del horario o de lugar de ejercicio de forma que, finalmente, el derecho devenga inútil, el sacrificio del derecho es excesivo. Y mucho más lo es la denegación del derecho de manifestación y el cambio sustancial y la hora del único derecho permitido, cual es el de concentración. De otra parte, si se mira desde el grado de afectación del interés del orden público o de satisfacción del mismo, solo se reducen a los trastornos y restricciones de la circulación de personas y vehículos, corte de tráfico o invasión de calzadas, o a que las actuaciones se concentren en determinadas zonas o calles de la ciudad, supone un grado de afectación leve. Lo que no sucede si el impacto en el orden público adquiere la característica de una:

"Obstrucción total de vías de circulación que, por el volumen de tráfico que soportan y por las características de la zona - normalmente centros neurálgicos de grandes ciudades-, provoquen colapsos circulatorios en los que, durante un período de tiempo prolongado, queden inmovilizados vehículos y se impida el acceso a determinadas zonas o barrios de la ciudad por imposibilidad de que la autoridad gubernativa habilite vías alternativas de circulación. En estos supuestos de colapso circulatorio con inmovilización e imposibilidad de acceso a determinadas zonas por inexistencia de vías alternativa, puede resultar afectado el orden público con peligro para personas o bienes si, por ejemplo, resulta imposibilitada la prestación de servicios esenciales con incidencia en la seguridad de personas o bienes, como son los servicios de ambulancias, bomberos, policía o urgencias médicas".

En el caso concreto, la autoridad gubernativa prohibió toda concentración y manifestación, permitiendo solo la concentración final, por lo que la STC 163/2006 establece la nulidad de la prohibición al entender, mediante el juicio de ponderación, que el sacrificio infligido a los derechos fundamentales era de un nivel intenso no siendo suficiente ni equivalente el beneficio reportado al orden público que, por otra parte, se juzga, como se ha dicho antes, como un interés de un peso específico menor. Así concluye que la resolución de la autoridad gubernativa "no cabe duda de que permite alcanzar el fin perseguido de la protección del orden público con integridad de personas y bienes”, si bien el rechazo de la afectación leve del derecho fundamental antes descrita (la única posible para salvaguardar su 
función en el caso concreto) que tenía como finalidad reducir el impacto del ejercicio de los derechos sobre el orden público, ha impedido ponderar ambas afectaciones en pie de igualdad o dotadas de una cierta equivalencia. Finalizando con la siguiente afirmación:

"En cuanto al juicio de proporcionalidad en sentido estricto, es decir, de comprobar si la medida era equilibrada por derivarse de la misma más beneficios para el interés general que perjuicios sobre el derecho de reunión, tampoco se supera dicho juicio por cuanto no se han dado en ningún momento razones fundadas sobre las que sustentar en el caso concreto el interés general que se trataba de preservar (las alteraciones del orden público con peligro para personas y bienes) y lo único manifiesto es el perjuicio que para el derecho de reunión supuso la eliminación de la concentración ante el Ministerio de Administraciones Públicas, es decir ante uno de los sujetos directos afectados, y la imposibilidad de desplazarse haciendo pública la protesta y la reivindicación programada hasta el otro punto de concentración”.

\section{CONCLUSIÓN}

Sin duda alguna que el juicio de ponderación puede ser criticado como procedimiento para solventar el conflicto entre derechos fundamentales entre sí o entre estos y otras libertades, principios y valores constitucionales debido a dos factores. De un lado, el aparente amplio margen de interpretación que existe en la aplicación del juicio de ponderación, de forma que, tratándose de sucesivos procesos valorativos, el campo para la indeterminación, la indefinición y la falta de seguridad jurídica es muy amplio; y, de otro lado, que estos amplios espacios de interpretación y de valoración acaban confiriendo un enorme poder decisional a los jueces que acaban convirtiéndose en los creadores de la norma y en los decididores de la entidad respectiva de los derechos fundamentales y de los intereses constitucionales en virtud de la aplicación del juicio de ponderación.

Empezando con la segunda objeción, es verdad que el juicio de ponderación abre un extenso campo a la discreción de los jueces, si bien ello no es sino consecuencia de su propia labor interpretativa, necesariamente cualificada cuando se trata de aplicar normas que contienen principios y valores, como sucede con todas las normas constitucionales. Si la única solución al conflicto, en los términos que se han venido planteando en este trabajo, requiere de varios procesos de valoración de entidad, peso respectivo, grado de afectación y de satisfacción de los intereses encontrados, resulta inevitable y adecuado que la solución de los conflictos en sede judicial. Residenciar aquí la solución del conflicto permite responder a la primera de las objeciones ya que la elaboración judicial, poniendo de manifiesto las valoraciones hechas y los criterios que se han utilizado para elaborarlas, al ir constituyendo un cuerpo de doctrina se convierte en un límite a la discrecionalidad judicial en el futuro. De forma que las resoluciones judiciales acumuladas, en la medida en que son públicas y pueden influir en posteriores sentencias, van conformando, a partir de los precedentes, un modo, cada vez más detallado y preciso, de aplicar los criterios a los que se recurre. Lo que determina un proceso de estabilización, reiteración y permanencia argumental que funcionará a su vez como límites que pueden ser controlados por la jurisprudencia constitucional. 